\title{
El VIH/SIDA en
}

África Austral:

situación, acciones

y retos ${ }^{*}$

$\mathrm{HIV} / \mathrm{AIDS}$ in

Southern Africa:

situation,

challenges and

actions

* Recibido: 5 de junio de 2012. Aprobado: 10 de julio de 2012.

Tla-Melaua, Revista de Ciencias Sociales. Facultad de Derecho y Ciencias Sociales. Benemérita Universidad Autónoma de Puebla, México / IssN: 1870-6916 / Nueva Época, Año 6 № 33, Octubre 2012 - Marzo 2013, pp. 126-141. 
África Austral es una de las regiones del continente africano con mayor incidencia del VIH/sIDA. En este sentido, el trabajo se enfoca en presentar algunas de las acciones emprendidas en la región a través de la Comunidad de Desarrollo de África Austral (SADC) mediante el análisis del Marco Estratégico 2003-2007 y de los casos de Botswana, Lesotho, Namibia y Swazilandia (BLNS) para combatir el virus del VIH/SIDA y hacer un balance general de los logros y retos ante la epidemia. El argumento central de este trabajo es que el combate coordinado entre los países mencionados y la SADC contra el VIH/SIDA sólo es posible, y así lo han entendido los Estados involucrados, mediante una estrategia de cooperación regional e internacional.

\section{PALABRAS CLAVE}

África Austral, SADC, BNLS, VIH/SIDA, cooperación regional.
Southern Africa is a region of the African continent with the highest incidence of HIV/AIDS. In this sense, the present work focuses on some of the actions undertaken in the region through the Africa Development Community (SADC) through the Strategic Framework 2003-2007 and the cases of Botswana, Lesotho, Namibia and Swaziland (BLNS) to combat the HIV/AIDS and make an overall assessment of the achievements and challenges facing the epidemic. The central argument of this article is that the coordinated combat, these countries and the SADC HIV/AIDS is only possible, and they have treated the states involved, through a strategy of sub regional and international cooperation.

\section{KEYWORDS}

Southern Africa, SADC, BNLS, HIV / AIDS, regional cooperation.

\footnotetext{
** Profesora Investigadora en la Facultad de Derecho y Ciencias Sociales de la Benemérita Universidad Autónoma de Puebla, México. (mracubana@yahoo.com.mx)
} 
1. Introducción

2. La Declaración de Maseru en 2003

3. Estrategia de Trabajo de la SADC contra el VIH/SIDA 2003-2007

4. Los casos de Botswana, Lesotho, Namibia y Swazilandia (BNLS)

5. Consideraciones finales

\section{INTRODUCCIÓN}

Uno de los desafíos que enfrenta África Austral es el combate al VIH/SIDA. Desde el conocimiento de la enfermedad a finales de los años setenta del siglo $\mathrm{XX}^{1}$, el VIH/SIDA se convirtió en un problema importante que obstaculizaría el progreso en la región con todas sus implicaciones económicas, políticas y sociales. A pesar de la concientización de la gravedad de la situación, los avances médicos reflejados en el descubrimiento de retrovirales a mediados de los 90, los fondos para la lucha contra el VIH/SIDA, entre otros elementos, el virus de inmunodeficiencia adquirida sigue siendo un flagelo para la vida de millones de africanos.

A más de 30 años, la epidemia se ha propagado a todos los rincones del mundo y África subsahariana se sitúa en el foco central del problema contando con 22,4 millones de personas que viven con el VIH/SIDA, representando el $67 \%$ del total de la carga mundial de la enfermedad. Países como Botswana, Lesotho o Sudáfrica resaltan en las cifras de prevalencia del virus con más del $20 \%$ de infectados, siendo la región meridional del continente africano la zona con el más alto porcentaje de infectados por el VIH/SIDA. ${ }^{2}$

\footnotetext{
${ }^{1}$ En el libro El remedio invisible, la autora Helen Epstein dedica uno de los capítulos a entender los misteriosos orígenes del SIDA y las diversas hipótesis al respecto. Sin pretender profundizar en este punto la autora denota que probablemente la pandemia global del SIDA se inició en la región de Kagera, una franja verde situada entre las rocosas colinas del valle del Rift, entre la orilla occidental del lago Victoria y las fronteras de Rwanda y Uganda en la década de 1970. Los investigadores creen que el VIH surgió en algún lugar de África occidental a principios del siglo XX y después se propagó lentamente por África central a la largo de décadas. Posteriormente, a finales de la década de 1970 se produjo la primera epidemia explosiva en Kagera y rápidamente se extendió a Rwanda, Burundi y el sur de Uganda. Desde allí, el virus siguió su camino hacia el este, a Tanzania y Kenia y hacia el sur del continente. Cabe destacar que en el 2007 se cumplieron 25 años desde que se desataron la epidemia y los rumores sobre los orígenes del virus y por qué se trasmite con tanta rapidez. En ciertos pueblos se esparcen aun, obstaculizando muchas veces los programas de investigación, tratamiento y prevención.

${ }^{2}$ Se calcula que alrededor de 40 millones de personas viven con el virus del VIH y más de 25 millones han muerto a causa de la enfermedad. Datos extraídos de Naciones Unidas/ SIDA. Ante este panorama no sólo africano sino mundial, la Organización de las Naciones Unidas en 2000 incluyeron dentro de la Declaración del Milenio como una de las prioridades la lucha contra el VIH/SIDA.
} 
Para ejemplificar la alta concentración de casos de la enfermedad en la región austral, podemos ver cómo Swazilandia registra las mayores prevalencias de VIH/SIDA a nivel mundial, con datos de $26 \%$ del virus en adultos de 15 a 49 años en el nivel nacional. Por otro lado, Sudáfrica, el polo de desarrollo de la región, cuenta con cerca de 5.5 millones de personas que viven con el VIH/SIDA, siendo el país con el mayor número de infecciones. Por esta situación, en África Austral la esperanza media de vida ha pasado de los 62 años en los años noventa del siglo pasado a menos de 50 en 2000. ${ }^{3}$ Esta es una de las razones fundamentales del porqué organismos regionales como la Comunidad de Desarrollo de África Austral (SADC) y algunos de los países que la conforman como Botswana, Namibia, Lesotho y Swazilandia (BNLS) han emprendido acciones políticas coordinadas para detener la epidemia y reducir las muertes por VIH/SIDA. La descripción de estas acciones es el primer objetivo de este artículo.

La SADC es uno de los organismos de integración más importante de África Austral. La Comunidad cuenta con más de 190 millones de habitantes. El organismo comprende a países como Angola, Botswana, Lesotho, Malawi, Mozambique, Namibia, Sudáfrica, Swazilandia, Zambia y Zimbabwe ubicados en el sur del continente. No obstante, la Comunidad comprende además países como la República Democrática del Congo del África Central y la República Unida de Tanzania, las Islas Mauricio, las islas Seychelles y Madagascar de la región oriental del continente. ${ }^{4}$

Ya entrados en el siglo XXI, para 2003, toda África Subsahariana destacaba por ser la región con mayor número de personas con VIH/SIDA (26.6 millones de personas) y con 2.3 millones de personas fallecidas. ${ }^{5}$ Específicamente dentro de la SADC, se encontraban países como Sudáfrica, Swazilandia y Botswana que poseían altas tasas de concentración de personas infectadas, mientras que las islas Seychelles y Mauricio se mantenían por debajo del $1 \%{ }^{6}$

\footnotetext{
${ }^{3}$ Gracia Calleja, Jesús M., "La epidemia del VIH/SIDA en el África Subsahariana: situación, impacto y progresos", en La salud en África: SIDA, cooperación al desarrollo y corrupción. Colección Cuadernos de trabajo sobre el desarrollo, SODEPAZ, pp. 37 y 38, memorias 2010. [Consulta: 23 de agosto de 2011] Disponible en: http://memoria2010.sodepaz.org/data/publicaciones/la_salud_en_africa.pdf.

${ }^{4}$ Hay que destacar que la Comunidad se creó el 17 de agosto de 1992 en Namibia como sucesora de la Conferencia de Coordinación para el Desarrollo de África Austral (SADCC), fundaba en Zambia el 1 de abril de 1980 y que entre sus postulados esenciales desde su fundación estaba la integración a los niveles más altos que comprendía los niveles económicos, políticos, militar y de seguridad. Ver: Rodríguez Añuez, Myrna, "La Comunidad de Desarrollo de África Austral: ¿Una alternativa para África del Sur?" en Salas Porras, Alejandra y Uscanga, Carlos (coords.), Desarrollo regional. Estrategias y Oportunidades, Universidad Nacional Autónoma de México, Facultad de Ciencias Políticas y Sociales, México, Gernika, 2008, pp. 348 y 355.

${ }^{5}$ SADC HIV and aids strategic framework and programme action 2003-2007. [Consulta: 23 de agosto de 2011] Disponible en: http://www.chr.up.ac.za/undp/subregional/docs/sadc3.pdf

${ }^{6}$ La zona subsahariana es la región más afectada por el SIDA. Según datos de la ONU en 2010 un 68\% de todas las personas infectadas con SIDA vivían en esta región. [Consulta: 24 de mayo de 2012] Dis-
} 
En otros datos, la edad promedio de los portadores del VIH/SIDA en la zona es de 15-49 años, ${ }^{7}$ siendo más afectado el sexo femenino debido a una de las nuevas formas de transmisión del virus: de madre a hijo. Esto ha traído consigo mayor mortandad y mayor número de huérfanos, razón por la cual la pandemia ha afectado de una u otra manera al $60 \%$ de la población en la región de la SADC.

Tomando en consideración estos datos generales y sumando otros ${ }^{8}$, nos viene la interrogante ¿por qué la incidencia del SIDA es tan elevada en África Austral y por qué se ha extendido tan rápidamente? ${ }^{9}$ Para encontrar respuestas a esta cuestión habría que considerar múltiples elementos empezando por el estigma asociado al SIDA; la reacción de los líderes africanos ante la visión y opiniones desde Occidente sobre la epidemia; ${ }^{10}$ la negación o la poca importancia que le otorgaron los líderes políticos a la epidemia en sus respectivos países, ${ }^{11}$ así como el carácter secundario que se le dio a los programas de prevención y alerta a la población en general sobre los

ponible en: http://www.unaids.org/es/resources/presscentre/pressreleaseandstatementarchive/2012/ march/20120327prunaidsnepad/. SADC HIV and aids strategic framework and programme action 2003-2007. [Consulta: 24 de mayo de 2012] Disponible en: http://www.chr.up.ac.za/undp/subregional/docs/sadc3.pdf.

${ }^{7}$ SADC HIV and aids strategic framework and programme action 2003-2007. [Consulta: 24 de mayo de 2012].Disponible en: http://www.chr.up.ac.za/undp/subregional/docs/sadc3.pdf.

${ }^{8}$ En 1985 prácticamente no existía ningún seropositivo en Botswana. Ya para 1992 el $10 \%$ de los adultos era portador del virus y hacia 2005 la cifra era de casi un $40 \%$. En Sudáfrica, la tasa de infección por VIH pasó de $5 \%$ en 1993 a 30\% en 2005. Hacia 2004, el 42\% de los adultos de Swazilandia eran seropositivos. Ver: Epstein, Helen, El remedio invisible. África, Occidente y la lucha contra el sida, Barcelona, Alba Editorial, 2007, p. 93.

${ }^{9}$ Sobre esta cuestión el historiador John Iliffe sostiene que la incidencia del SIDA es más elevada en África porque el virus apareció allí en primer lugar. Definitivamente ha trascurrido tiempo para que la epidemia ya no sólo sea una problemática a enfrentar por los africanos sino que se ha arraigado en otros países. Iliffe, John, The African AIDS Epidemic: A History, Oxford, Oxford University Press, 2006.

${ }^{10}$ Un ejemplo de esto fue cuando en 1989 el demógrafo australiano John Caldwell y sus colegas argumentaron que el virus se estaba extendiendo tan rápidamente en África porque sus habitantes tenían un sistema sexual único, caracterizado por elevadas tasas de relaciones sexuales casuales y prematrimoniales. Apuntaba al deseo, enraizado en la cultura de la tradición de la poligamia y a la relativa libertad de las mujeres africanas. Está claro que este tipo de declaraciones desató una polémica no sólo porque revestía profundos estereotipos sobre la sexualidad africana sino porque los estudios no sugerían que los africanos fueran más promiscuos que la población heterosexual de otras partes del mundo. G. Caldwell, John, Caldwell, Pat y Quiggin, Pat, "The African Sexual System: Reply to LeBlanc et al.", Popular Development Reviewe, No. 17, 3 de septiembre de 1991, pp. 506-515.

${ }^{11}$ Muestra de ello es que en el 2000 el Ministerio de Sanidad sudafricano calculó que cerca de 4 millones de sudafricanos eran seropositivos y que se contagiaban a diario unas mil setecientas personas. El VIH llevaba más de una década en el país pero, al igual que gran parte de África, tanto el gobierno como la opinión pública no habrían prestado demasiada atención a la crisis. El entonces presidente sudafricano Thabo Mbeki era uno de los Jefes de Estado conocido que se había tomado en serio la opinión de los disidentes del SIDA y todos pensaban que había perdido el juicio declarando métodos para combatir el SIDA como el aceite de oliva o la remolacha. En 1999 declaró ante el Parlamento que los antirretrovirales no sólo eran caros sino tóxicos, y él y su círculo de gobierno se embarcaron en una cruzada contra los antirretrovirales dejando morir a cientos de personas. Para suerte de los sudafricanos, en 2002 el gobierno sudafricano dio un giro en su política sobre el SIDA. Los observadores creen que las ideas de Mbeki seguían siendo las mismas pero que el cambio se debió sobre todo a la presión de los activistas. Desde entonces se puso en marcha programas de tratamiento con drogas antirretrovirales en todo el país. 
riesgos del SIDA. ${ }^{12}$ Igualmente, la incidencia de relaciones sexuales simultáneas prolongadas ${ }^{13}$ resultó ser un factor importante en la propagación del VIH/SIDA. En este sentido, el trabajo ${ }^{14}$ se enfoca en presentar algunas de las acciones emprendidas en la región a través de la SADC mediante el Marco Estratégico 2003-2007 y los casos de Botswana, Lesotho Namibia y Swazilandia (BLNS) para combatir el virus del VIH/SIDA y hacer un balance general de los logros y retos ante la epidemia. El argumento central de este trabajo es que el combate coordinado entre los países mencionados y la SADG contra el VIH/SIDA sólo es posible, y así lo han entendido los Estados involucrados, mediante una estrategia de cooperación regional e internacional.

\section{La declaración de Maseru en 2003}

Como hemos visto, la región austral que comprende a la Comunidad es, para perjuicio de su gente, una de las zonas con más incidencia del VIH/SIDA. Por tal razón, aunque por mucho tiempo la negación parecía ser la política oficial de algunos gobiernos africanos de la región, la rápida propagación del virus y su alto impacto empezaron a alarmar a la sociedad en general.

La primera acción formal adoptada por los Estados miembros de la SADC fue el Código sobre el VIH/SIDA y el empleo (1997) y el Protocolo de Salud de la SADG (1999). ${ }^{15}$ Estos fueron ejercicios enmarcados en las posibilidades de colaboración dentro del esquema de la cooperación subregional.

\footnotetext{
${ }^{12}$ Un elemento que hay que considerar relacionado con la propagación del virus está vinculado con un legado colonial en la zona. Desde principios del siglo XIX, la economía del Sur de África estuvo vinculada a las nuevas minas de oro y diamantes de Sudáfrica, relacionada incluso a países más alejados de la región como Tanzania. Las autoridades coloniales británicas establecieron un impuesto por cada casa obligando a millones de africanos a dejar sus aldeas como mano de obra durante meses o años. Las consecuencias de esta política fue devastadora para las familias africanas, incrementando la incidencia de enfermedades como la sífilis o la gonorrea en el contexto de prostitutas, mineros y vagabundos. Los migrantes traían así sus enfermedades de trasmisión sexual y cuando el VIH/SIDA comenzó a extenderse en la década de 1980 recorrió las mismas rutas de propagación.

${ }^{13}$ Según estudios, las relaciones sexuales simultáneas son mucho más peligrosas porque vinculan a los individuos en una enorme red de relaciones sexuales que dan lugar a condiciones ideales para la rápida propagación del VIH/SIDA. Ver: Epstein, Helen. El remedio invisible. África, Occidente y la lucha contra el sida, Barcelona, Alba Editorial, 2007, p. 101.

${ }^{14}$ Este trabajo es un acercamiento a un proyecto de investigación mucho más amplio, cuyo objetivo principal es el estudio de los procesos de integración regional en África Subsahariana. Una primera versión fue presentado en el Congreso de la Asociación Mexicana de Estudios Internacionales (AMEI) del año 2011. Para ese resultado se contó con la colaboración en la investigación de la estudiante Ana Karen Bautista de la Licenciatura en Relaciones Internacionales de la Facultad de Derecho y Ciencias Sociales, BUAP.

${ }^{15}$ Moyo, Admark, "The protection and promotion of socio-economic rights in the SADC region", en ESR Review, Vol. 11, No. 3, 2010, p. 14. [Consulta: 2 de junio del 2012 ] Disponible en: http://www. communitylawcentre.org.za/projects/socio-economic-rights/Research $\% 20$ and $\% 20$ Publications/ ESR\%20Review/Volume\%2011\%20No\%203\%20-\%202010.pdf\#page=12.
} 
Otra de las primeras acciones que se emprendieron correría a cargo del Banco Mundial que, en 1999, diseñó una estrategia global para enfrentar la epidemia en África Subsahariana. ${ }^{16}$ Sin embargo, esta acción de cooperación internacional en particular, a pesar de haber logrado algunos éxitos, no estuvo exenta de críticas, fundamentalmente porque la estrategia diseñada estaba basada en la experiencia de los países desarrollados e industrializados, y enfocada a ciertos grupos vulnerables cuando en África Subsahariana y en la región Austral la epidemia era en realidad un problema de salud pública generalizado y necesitaba una aproximación no focalizada. ${ }^{17}$

Para los Estados miembros de la SADG el tema se volvió altamente preocupante dada la masividad del contagio del VIH/SIDA. Bajo este panorama, el 4 de julio de 2003 los Estados miembros de la Comunidad publicaron la Declaración Maseru, ${ }^{18}$ cuya firma significaba el compromiso conjunto de cooperación subregional para luchar contra el VIH/SIDA en la región. De igual manera, se estableció en dicha declaración la necesidad de un enfoque integral para la lucha contra esta epidemia incluyendo no sólo aspectos sanitarios, sino también aspectos más amplios relacionados con el desarrollo, la mejora de las condiciones de vida y la educación.

Con esta declaración, la organización subregional dio a conocer la situación de la Comunidad ante el continuo crecimiento e impacto de VIH/ SIDA en la zona y estableció las medidas que junto con la participación de sus miembros llevarían a cabo. Igualmente se contempló la formulación de programas que incluyeran la investigación, el monitoreo, la prevención y el apoyo a personas enfermas del virus. Éstos se determinarían sobre la base de cinco áreas estipuladas por la organización como las principales para contrarrestar y disminuir la pandemia:

- La prevención y movilización social: Aquí se toma en consideración a los gobiernos, a la iniciativa privada y a la sociedad en general en la participación de los programas. Todos ayudarían en la promoción

\footnotetext{
${ }^{16}$ World Bank, The World Bank's Commitment with HIV/AIDS in Africa. Our Agenda for Action 2007-2012, Washington, The International Bank for Reconstruction and Development/World Bank, 2008.

${ }^{17}$ De Cock, Kevin M., Mbori-Ngacha, Dorothy \& Marum, Elizabeth, "Shadow on the continent: public health and HIV/AIDS in Africa in the 21st century", The Lancet, Volume 360, Issue 9326, 6 July 2002, Pages 67-72.

${ }^{18}$ La Declaración de la Comunidad de Desarrollo de África Austral sobre VIH y SIDA, también llamada Declaración Maseru por haberse firmado en la cuidad de Maseru en Lesotho. En comparación con la precedente Declaración de la Unión Africana sobre VIH/SIDA, tuberculosis y otras enfermedades infecciosas, esta declaración no hace referencia a la cancelación de la deuda externa como requisito fundamental para la mitigación del impacto del SIDA en la región. [Consulta: 6 de junio del 2012]. Disponible en: http://www.arasa.info/index.php?option=com_content\&view=article\&id=131:sadchivaids-declaration-maseru-declaration $\&$ catid $=52$ :declarations $\&$ Itemid $=15$

Southern African Development Community, "Maseru Declaration on the fight against HIV/AIDS in the SADC region", Julio.4, 2003. [Consulta: 9 de junio de 2012]. Disponible en: http://www.sadctribunal.org/docs/HIV-AIDS.pdf.
} 
de una educación sexual en la cual los servicios de salud serían los encargados de dar información sobre la enfermedad y proveer los métodos anticonceptivos para un comportamiento sexual responsable. De igual forma, se invitaba a fortalecer la unidad familiar y el mantenimiento de los valores culturales como la igualdad.

- El mejoramiento de la atención, el acceso a asesoramiento, pruebas, tratamiento y apoyo: En este punto primeramente se buscaba que dentro de la sociedad se rompiera el silencio y el tabú en torno al VIH/SIDA. En este sentido, se pretendía evitar la discriminación hacia las personas portadoras siendo asesoradas correctamente para tratar de evitar la exclusión. De igual manera, los servicios de salud debían ser fortalecidos para brindar una buena atención y promover el financiamiento regional necesario para obtener la tecnología y los medicamentos y que éstos pudieran adquirirse a un precio accesible para las personas portadoras.

- La atención al desarrollo y la mitigación de los efectos del VIH/ SIDA: La prevención, el tratamiento, la atención, el apoyo, la nutrición y la seguridad alimentaria serían las acciones que ayudarían a hacer frente a su propagación cuyo impacto se reflejaría en las esferas social, económica e incluso política.

- La intensificación de la movilidad de recursos: En esta sección cada Estado miembro de la SADC se comprometía a destinar el 15\% de su presupuesto anual al sector salud. ${ }^{19}$ De igual manera, se buscaba obtener ayuda de la comunidad internacional, tanto económica como técnica, incluyendo la participación de organizaciones privadas que contribuyeran con fondos económicos.

- El fortalecimiento de los mecanismos institucionales: Se hace referencia a los mecanismos relacionados con el seguimiento y la evaluación de los programas, ya que los resultados serían útiles en el intercambio de información dentro de la región, y podría ser un referente no sólo dentro de esta zona sino en todo el continente. ${ }^{20}$

Estas áreas de trabajo guiaron las acciones de la Comunidad desde el 2003 en las políticas y programas que se han puesto en marcha para contrarrestar la presencia del VIH/SIDA en la región. Incluso, la Declaración de Maseru contempla en su artículo 4 una serie de consideraciones legales que obliga

\footnotetext{
${ }^{19}$ Southern African Development Community, "Maseru Declaration on the fight against HIV/AIDS in the SADG region", Julio 4, 2003. [Consulta: 6 de junio de 2012] Disponible en: http://www.sadctribunal.org/docs/HIV-AIDS.pdf

${ }^{20}$ Southern African Development Community (SADC) regional BLNS hta (cbs/hts) sti/hiv and aids, strategy and program of action 2003-2006. [Consulta: 29 de mayo de 2012]. Disponible en:http:// www.sadc.int/sadcaidsinfo/docs/techdocs/Strategy $\% 20$ and $\% 20$ Program $\% 20$ Action.pdf
} 
a los miembros de la SADC a movilizar recursos que beneficien la salud de la población, destinar — tal y como se aceptó en la Declaración de Abuja15\% del presupuesto de los Estados para aplicarse en el sector salud. También contempla en su modelo legal la obligación de los Estados de otorgar medicamentos a las personas infectadas de VIH/SIDA y preservar sus derechos a tener una vida sexual activa, formar familias y procrear, alcanzando así también una gama importante de Derechos Humanos. ${ }^{21}$

Quizá una de las motivaciones más importantes para enfrentar la epidemia de manera colectiva y coordinada, además de los efectos perniciosos contra la población, era la propia naturaleza de debilidad de los Estados africanos para afrontar el reto individualmente. Otra motivación era que el impacto del VIH/SIDA en esos países también estaba dejando una profunda huella de crisis en la productividad, el desarrollo y las cifras macroeconómicas. ${ }^{22}$

A partir de la Declaración de Maseru los Estados miembros de la Comunidad establecieron agendas y compromisos de trabajo más precisos como los que a continuación se describen.

\section{Estrategia de TRABAjO de la SADC CONTRA EL VIH/SIDA 2003-2007}

Un ejemplo de la aplicación de los puntos antes mencionados en el nivel subregional fue la Estrategia de Trabajo referido en el Marco Estratégico 2003-2007, en el que se plantearon las siguientes metas:

- Lograr la reducción de la prevalencia del VIH al 25\% en la población joven.

- Elaborar y aplicar integralmente programas de atención, apoyo y tratamiento, incluyendo la manera de hacer frente a las limitaciones de recursos, como infraestructura sanitaria deficiente y la problemática del estigma y la discriminación.

- Mitigar el impacto de la situación socio-económica, especialmente en la prestación de apoyo para los huérfanos y otras personas vulnerables mediante el desarrollo y la implementación de estrategias para el desarrollo social de apoyo, tales como vivienda, educación, nutrición, salud y servicios sociales.

\footnotetext{
${ }^{21}$ Admark, op. cit., p. 14. La Declaración de Abuja sobre VIH/SIDA, tuberculosis y otras enfermedades infecciosas relacionadas aprobada por la Unión Africana en abril del 2001.Ver: http://www.un.org/ga/ aids/pdf/abuja_declaration.pdf

${ }^{22}$ Patterson, Amy S. (editor), The African State and AIDS Crisis, Great Britain, Ashgate Publishing Limited, Aldershot, 2005, p. 4.
} 
- Desarrollar e implementar políticas, estrategias y programas sobre el VIH/SIDA en sectores claves como la educación y la agricultura. ${ }^{23}$

Estos objetivos fueron apoyados por los propios gobiernos de la Comunidad tomando como base el respeto a los derechos humanos y la igualdad de género, considerando que las mujeres son las más afectadas.

Este Marco de trabajo se dirigía al desarrollo de la atención, tratamiento (adquisición de medicamentos), nutrición de las personas afectadas y apoyo a los huérfanos. Igualmente prestaban atención a la prevención con acceso a pruebas voluntarias, información sobre la enfermedad, sus formas de contagio, entre otras. Las actividades estuvieron dirigidas por el Departamento de Planificación Estratégica, Género y Armonización de Políticas creado para este rubro y monitoreado por el Técnico Multisectorial del VIH/SIDA, el cual se encargaba de vigilar y evaluar el seguimiento del plan de trabajo. Todo esto apoyado por una extensa red de información sobre el tema, con base en datos regionales y evaluaciones de los planes individuales de los países para combatir el VIH/SIDA.

En materia de finanzas, los comités de la SADC tenían asignaciones especiales para este rubro e igualmente se obtuvieron otros recursos por parte de la cooperación subregional entre los propios Estados y por apoyos de otras organizaciones tanto públicas como privadas, algunas de ellas internacionales.

Estos trabajos se realizaron bajo el mando del Subcomité Técnico Multisectorial de la Comunidad que trabaja en este tema. Además cuenta con el apoyo de múltiples instituciones como el Programa de las Naciones Unidas para el Desarrollo (PNUD), la Organización Mundial de la Salud (OMS), el Banco Mundial (BM), el Fondo de Población de las Naciones Unidas, la Organización Internacional de Migraciones, el Programa de las Naciones Unidas para VIH/SIDA, Organizaciones No Gubernamentales (ONGs), incluso con el apoyo de gobiernos europeos, en especial del Reino Unido. ${ }^{24}$

Para el logro de una correcta aplicación del Marco de trabajo, éste se dividió en dos secciones: Una ponía énfasis en la realidad de la zona SADG en cuestión del virus del VIH/SIDA, incluyendo el análisis de cómo impactaría la puesta en marcha del programa, en tanto que la otra se encargaría del desarrollo de los programas incluyendo costos.

Es por esto que a pesar de que cada gobierno buscaba implementar un modo de trabajo para reducir la presencia del VIH/SIDA en su territorio,

\footnotetext{
${ }^{23}$ Southern African Development Community (SADG) regional BLNS hta (cbs/hts) sti/hiv and aids, strategy and program of action 2003-2006. [Consulta: 24 de mayo de 2012]. Disponible en:http:// www.sadc.int/sadcaidsinfo/docs/techdocs/Strategy\%20and\%20Program\%20Action.pdf

${ }^{24}$ Sadc hiv and aids strategic framework and programme action 2003-2007. [Consulta: 12 de septiembre de 2011] Disponible en: http://www.chr.up.ac.za/undp/subregional/docs/sadc3.pdf
} 
la SADC como organismo regional hizo hincapié en buscar la solución a partir de los esfuerzos colectivos de la zona, esto es, mediante esquemas de cooperación subregional, todo en función de trabajar en recursos financieros y humanos necesarios para poner en práctica los programas planeados.

\section{LOS CASOS DE BOTSWANA, LESOTHO, NAMIBIA Y SWAZILANDIA (BNLS)}

Dentro de la Declaración Maseru y de este Marco Estratégico, los países BNLS $^{25}$ emprendieron acciones a partir de la realidad que se vivía en la subregión respecto al impacto del VIH/SIDA. Estos países representan un $17 \%$ de la población total mundial infectada por el virus ${ }^{26}$ : en países como Namibia la tasa de prevalencia de adultos infectados de $15-49$ era de $22.5 \%$, en Lesotho 31\%, en Swazilandia 33.4\% y en Botswana 38.8\%.$^{27}$

Al detectarse esta problemática, tomando en consideración los altos niveles de movilidad migratoria de la zona - generada por la búsqueda de una mayor estabilidad económica-, las acciones pusieron énfasis en este fenómeno, tomando en cuenta que el virus no respeta fronteras físicas. En este sentido, las acciones estuvieron dirigidas a fortalecer el entorno propicio en el que mujeres, hombres y jóvenes más vulnerables ${ }^{28}$ en la zona pudieran reducir el riesgo en relación al VIH/SIDA.

Los objetivos prioritarios de las acciones estaban dirigidos al establecimiento de servicios de salud con el equipo y medicinas necesarias, atención en la prevención con la difusión de información y la conciencia del uso del condón como método anticonceptivo.

En este sentido, desde 2007 las Estadísticas del Programa Conjunto de las Naciones Unidas del VIH/SIDA mostraban cambios positivos en la presencia del VIH/SIDA. En Botswana y Swazilandia se ha visto una disminu-

\footnotetext{
${ }^{25}$ Países con economías vinculadas estrechamente con Sudáfrica. Botswana, cuyo nombre oficial es República de Botswana, es un Estado sin litoral del sur de África. Geográficamente el 70\% de su superficie está cubierta por el desierto de Kalahari y obtuvo su independencia en 1966 por el Reino Unido. Cuenta con una población de 1.067.773 habitantes. Namibia, oficialmente República de Namibia, es un país del sudoeste de África que ocupa el territorio de lo que fue conocido hasta la década de 1960 como África del Sudoeste, obteniendo su independencia de Sudáfrica en 1990. Cuenta con una población de 2.324.004 habitantes. Lesotho, cuyo nombre oficial es Reino de Lesotho, geográficamente situado como un enclave dentro de Sudáfrica, obtuvo su independencia en 1966 por el Reino Unido. Cuenta con una población de 2.193.843 habitantes. Swazilandia, oficialmente el Reino de Swazilandia, es un pequeño país sin salida al mar en el Sur de África que obtuvo su independencia en 1968 por el Reino Unido. Cuenta con una población de 1.067.773 habitantes.

${ }^{26}$ Southern African Development Community (SADG) regional blns hta (cbs/hts) sti/hiv and aids, strategy and program of action, september 2003-2006. [Consulta: 23 de marzo de 2012]. Disponible en: http://www.sadc.int/sadcaidsinfo/docs/techdocs/strategy $\% 20$ and $\% 20$ program $\% 20$ action.pdf ${ }^{27}$ Ídem.

${ }^{28}$ Los más vulnerables son aquellos sectores con mayor movilidad como camioneros, trabajadores sexuales y mineros.
} 
ción de la prevalencia del virus tanto en la zona urbana como rural, en tanto que en Lesotho descendió en la zona rural y en Namibia se reflejó en ambas esferas una disminución de la presencia del virus.

Uno de los puntos a tomar en cuenta para el logro de estos resultados es, sin duda, el compromiso político de los gobiernos en la lucha contra el VIH/SIDA. En una entrevista concedida a ONUSIDA en 2010, Richard Malthare, director nacional de la Agencia Nacional de Coordinación del Sida de Botswana, consideró que la política de su país había logrado éxitos significativos por las siguientes razones:

- En el ámbito de la gobernanza, hay una firme voluntad política y un liderazgo en la respuesta al SIDA. Esto se ha traducido en una asignación interna de recursos económicos que abarca entre el 70\% y el 90\% de las necesidades de la respuesta nacional.

- Se percibe un claro éxito debido a los ambiciosos programas de tratamiento antirretroviral y de prevención de la transmisión materno infantil (PTMI), que tienen unas tasas de cobertura superiores al 93\% y al 94\%, respectivamente. La calidad de vida de las personas que viven con el VIH ha mejorado y el número de muertes por SIDA evitadas se ha reducido en un significativo 50\% desde el comienzo del programa de tratamiento. La transmisión materno infantil se ha reducido por debajo del $4 \%$.

- El uso de los servicios de asesoramiento y de pruebas también es alto, con una tasa del 56\% entre las personas sexualmente activas. De igual manera se ha visto un aumento del 90\% en la realización de pruebas en los servicios de salud. ${ }^{29}$

Para Malthare "el caso es que Botswana ha sido capaz de detener la propagación del VIH, cuya tasa de prevalencia del VIH en adultos pasó del $24,7 \%$ en 2001 al 13,2\% en 2009. Sin embargo, aún no se ha llegado al objetivo nacional actual de reducir las tasas de incidencia en un 50\% hasta 2016". 30

Por supuesto, Botswana presenta también limitaciones importantes como la existencia de "políticas que dificultan el acceso al tratamiento para los recién nacidos que no son ciudadanos. Si el padre es ciudadano y la madre no, el niño no puede acceder al tratamiento y la madre no puede acceder al plan Prevención de la Transmisión del VIH de Madre a Hijo. Además, Botswana no tiene una ley que aborde el problema del VIH/SIDA

${ }^{29}$ UNAIDS, "País destacado, Botswana: La respuesta al sida ha tenido un efecto catalizador en el fortalecimiento de nuestro sistema de salud". [Consulta: 25 de agosto de 2011). Disponible en: http://www. unaids.org/es/resources/presscentre/featurestories/2010/september/20100921fsmdgbotswanaqa/ ${ }^{30}$ Ídem. 
en los lugares de trabajo, por lo cual los patronos pueden discriminar a los empleados".31

Por su parte, Lesotho ha sufrido los estragos de la epidemia del VIH/ SIDA acompañada por la caída de los precios de los diamantes y la pérdida de exportaciones textiles. Mientras, el crecimiento del producto interno bruto fue de sólo 0,9\% en 2009, cuando en 2006 había sido de 6,5\%, indicó el Banco Mundial, agregando que tres de cada cinco niños y niñas de Lesotho viven en la miseria, y uno de cada cuatro es huérfano. ${ }^{32}$ Respecto a la epidemia del VIH/SIDA, Lesotho tiene uno de los índices más altos, tema que se multiplica debido a una gran población migrante que entra al país para trabajar en las minas y esa población flotante termina por volverse altamente vulnerable a la epidemia. ${ }^{33}$

Tanto para Lesotho como para su vecino Swazilandia, buena parte de las esperanzas para combatir el VIH/SIDA están fundadas en la cooperación internacional como ocurriera en 2004 cuando se crearon centros para el tratamiento de la enfermedad "a través de la colaboración entre los gobiernos de los dos países, la empresa Bristol-Myers Squibb de Nueva York y Baylor College of Medicine de Houston, Estados Unidos. Para ello, ambos centros contarían con fondos procedentes del programa Secure the future, de la empresa estadounidense y contarían con personal conjunto de Baylor y de Lesotho, Swazilandia y del sur de África". ${ }^{44}$

En Swazilandia quizá el mayor fracaso sea en el terreno de las políticas educativas de salud. En una encuesta realizada en 2007 se arrojaron los siguientes datos:

- El 99\% de los participantes del estudio decían conocer el SIDA, pero la mitad admitió practicar el sexo sin preservativos y tener varias parejas sexuales.

- Los hombres tienen un 23\% más de probabilidades de tener relaciones sexuales con más de una pareja en el último año, mientras que las mujeres tienen más probabilidades de haber mantenido relaciones sexuales antes de los 24 años.

- Apenas un 12\% de las familias suazis declararon usar preservativos como forma de planificación familiar, mientras que el 17\% de las

\footnotetext{
${ }^{31}$ Motseta, Sello, "Éxitos y fracasos, según de donde se mire", IPSNOTICIAS. [Consulta: 18 de agosto de 2011 ] Disponible en: http://ipsnoticias.net/nota.asp?idnews=91409, 2009.

${ }^{32}$ AFROL NEWS, "Lesotho Enclave de pobreza, hambre y sida". [Consulta: 18 de agosto de 2011] Disponible en: http://www.afrol.com/es/articulos/16549 (10/11/2005).

33 AFROL NEWS, "Comienza programa para reducir la vulnerabilidad del VIH/SIDA en Lesotho" [Consulta: 15 de agosto de 2011] Disponible en: http://www.afrol.com/es/articulos/16549 (13/06/2005). 34 AFROL NEWS, "Lesotho y Swazilandia contarán con centros para el tratamiento de VIH/ SIDA. [Consulta: 26 de agosto de 2011] Disponible en: http://www.afrol.com/es/articulos/14639 $(27 / 10 / 2004)$.
} 
mujeres usaban anticonceptivos inyectables y un 10\%anticonceptivos en comprimidos. ${ }^{35}$

Namibia es un caso particular porque su población apenas llega a los 2 millones de personas y podría tener un nivel de ingresos alto por la explotación de los yacimientos de uranio, diamantes y la industria de la pesca. Sin embargo, "17,8\% de las mujeres embarazadas son seropositivas y algunos de los mayores desafíos a los que se enfrentan las comunidades rurales a la hora de acceder al tratamiento, cuidado y servicios de apoyo son el estigma, la discriminación, y las normas y prácticas culturales". ${ }^{36}$ Nuevamente el mayor obstáculo en la región para combatir el VIH/SIDA es la pobre educación y las trabas o prejuicios culturales.

Desde la Declaración Maseru, el seguimiento y combate al VIH/SIDA en los países BLNS y en la Comunidad en general siguen siendo de las mayores prioridades. Aun cuando dichas acciones han ayudado a reducir el número de personas portadoras del virus y en cuanto a los ya infestados han logrado darles acceso a los antirretrovirales para mejorar su calidad de vida, es inevitable señalar que todavía queda mucho por hacer.

A pesar de que la aparición de nuevos casos de VIH/SIDA, estos tienden a estabilizarse. Incluso, como vimos en algunos países, muestran signos de retroceso, lo cual es resultado de las iniciativas de prevención dirigidas a nuevas infecciones. Los datos son algo esperanzadores pero no debemos olvidar que aun en la región la tasa de infección sigue siendo alta en adultos y sobre todo en niños, mujeres y jóvenes. La necesidad de aplicar adecuadamente una terapia preventiva y el uso de la terapia antirretroviral debe seguir siendo una prioridad para los gobiernos. Los progresos en esta materia han posibilitado la reducción de trasmisión de la madre al niño durante el embarazo, el parto o la lactancia.

Aun cuando el incremento del gasto por los gobiernos y agentes internacionales se ha hecho latente, todavía las carencias en la gestión, la infraestructura y alcance de los sistemas de salud- sobre todo en las zonas ruralesestán presentes. Por eso, la capacitación del personal sanitario, la formación de agentes de salud y el fortalecimiento de servicios de salud deben seguir siendo considerados fundamentales por los gobiernos para un mejor logro en el combate del VIH/SIDA.

\footnotetext{
${ }^{35}$ AFROL NEWS, "Suazilandia: todavía la mayor seroprevalencia del mundo".[Consulta: 26 de agosto de 2011] Disponible en: http://www.afrol.com/es/articulos/25975 (13/07/2007).

${ }^{36}$ PNUD, "El PNUD entabla conversaciones con las comunidades de Namibia sobre VIH/SIDA, [Consulta: 26 de agosto de 2011] Disponible en: http://content.undp.org/go/newsroom/2009/november/undp-engages-namibian-communities-in-conversation-on-hiv-aids.es?src=print\&lang=es (30/11/2009).
} 
Sabemos que el VIH/SIDA, unido a otras circunstancias, como las crisis económica y alimentaria, la pobreza, el acceso limitado a los servicios básicos y el aumento de movimientos migratorios, entre otros, crea condiciones que favorecen la propagación de la infección afectando fundamentalmente a jóvenes sexualmente activos que se encuentran en las edades más productivas de sus vidas. En este sentido, los gobiernos de África Austral saben que deben seguir trabajando en las medidas preventivas, concientizando, por una parte, la necesidad del uso del condón y la modificación de la conducta sexual y, por la otra, ampliando el acceso a los tratamientos antirretrovirales para los infestados. Este es el terreno de las políticas públicas en materia de salud que los Estados implementan tratando de coordinar esfuerzos basados en diversos esquemas de cooperación regional. Por un lado, las medidas sanitarias conjuntas se simplificarían administrativamente pero, por el otro, cada gobierno debe también afrontar el tema con sus poblaciones respectivas con campañas de educación, tolerancia y concientización.

Ante los múltiples obstáculos y desafíos que aun plantea el combate al VIH/SIDA en África Austral, hay una alternativa real para vislumbrar el control de la epidemia en la región afrontando los diversos factores que inciden en la problemática. Una única línea de acción no será suficiente para ese logro. Se necesitará seguir trabajando de manera integral y multifactorial. Los esfuerzos, el compromiso de los gobiernos y la sociedad, con el apoyo financiero tanto regional como internacional, seguirán ayudando en la lucha contra el VIH/SIDA.

\section{CONSIDERACIONES FINALES}

Si bien es cierto que la realidad del impacto del VIH/SIDA en África Austral es una problemática aun sin solución definitiva, tomando en cuenta que continúa siendo la región más afectada, las acciones emprendidas por los Estados han ayudado aun con resultados parciales a disminuir su impacto.

Así como la pandemia del VIH/SIDA en África Austral afecta a los sistemas de salud, también tiene un impacto significativo en el crecimiento económico, la estabilidad política y el nivel de dependencia hacia otros países con mayor desarrollo económico y tecnológico - como el caso de los países BNLS hacia Sudáfrica- Por lo tanto, es un problema que se tiene que enfrentar desde muchos frentes, desde la prevención hasta el mejoramiento de la calidad de vida de los enfermos.

Es así que tanto los Estados Miembros de la Comunidad de Desarrollo de África Austral como los de la Unión Africana ${ }^{37}$ están conscientes de

\footnotetext{
${ }^{37}$ En julio de 2012, la Unión Africana lanzó una nueva hoja de ruta para combatir el VIH/SIDA, así como la malaria y la tuberculosis. El marco fue la decimonovena reunión de la Unión Africana en
} 
las implicaciones de la problemática del VIH/SIDA en el continente, que lamentablemente involucra y determina otras situaciones, las cuales no permiten el desarrollo en muchos países. La presencia y las consecuencias de la pandemia afectan y deterioran la expectativa de vida, incrementan el analfabetismo y la poca afluencia a los niveles escolares más básicos. De igual forma, disminuye los niveles de educación en los niños debido a que se ve afectada la capacidad educativa por la mortalidad entre educadores, maestros y personas alrededor del sector educativo. Reduce los sectores económicos y afecta la capacidad social a causa también de la gran mortandad que existe. Todas estas situaciones desencadenantes crean una desestabilización sociopolítica en los países, lo que nos lleva a un escenario poco alentador.

No obstante, consideramos que la subregión del África Austral ha dado pasos importantes como el caso ejemplificado en este trabajo, que ha reducido su nivel de contagio y muerte a causa del VIH/SIDA y ha implementado programas de cooperación que han ayudado considerablemente a reducir sus efectos negativos. Aun así no podemos pasar por alto los múltiples fracasos de programas contra el VIH/SIDA financiados por donantes donde muchas veces y, quizás involuntariamente, se reforzó el estigma, la vergüenza y el prejuicio que rodea esta enfermedad.

Sabemos que hay muchos factores tanto internos como externos desde el punto de vista económico, político y social que dificultan la resolución rápida de este fenómeno que afecta profundamente la vida de los africanos. Por tanto, estamos ante una problemática compleja que necesita de mucho esfuerzo, voluntad política, consistencia, recursos económicos, entre otros, para llevar adelante su total solución. Sin duda, las acciones emprendidas por la Comunidad y especialmente por los países BNLS incitan a seguir trabajando y formando conciencia de la responsabilidad de que los Estados y la sociedad en general, tomen atención y se ocupen de la lucha contra el VIH/SIDA. En este sentido, la Comunidad de Desarrollo de África Austral ha demostrado ser un proceso de integración que ha contemplado en su agenda el combate al VIH/SIDA y sus Estados Miembros siguen trabajando mediante diversos esquemas de cooperación para hacer frente a esta problemática regional común.

\footnotetext{
Etiopía y en el documento se establecieron tres prioridades: (1) gestión sanitaria; (2) financiación diversificada; y (3) acceso a los medicamentos. La hoja de ruta fue refrendada durante la $67^{\text {a }}$ Sesión de la Asamblea General de las Naciones Unidas en Nueva York en septiembre de 2012 y así como se insistió en cumplir las prioridades antes mencionadas, también se hizo referencia a los compromisos sanitarios adquiridos en los Objetivos de Desarrollo del Milenio. ONUSIDA, "ONUSIDA informa de un descenso de más del 50\% en los casos de nuevas infecciones por el VIH en 25 países, a tan solo 1000 días para que los países deban haber cumplido los objetivos mundiales en materia de sida". [Consulta: 17 de septiembre 2012] Disponible en: http://www.unaids.org/es/resources/presscentre/pressreleaseandstatementarchive/2012/november/20121120prresults/
} 